\title{
Zorgverzekeraars en preventie: implementatie van de GLI's
}

\author{
Madelon Johannesma · Geert van Hoof
}

Published online: 18 February 2019

(C) The Author(s) 2019

\begin{abstract}
Al in 2009 onderkende het Zorginstituut dat je verandering van leefstijl moet zien als geneeskundige zorg en dat deze dus in het basispakket thuishoort. Het ontbrak zorgaanbieders en zorgverzekeraars echter aan voldoende duidelijkheid over inhoud en omvang van een gecombineerde leefstijlinterventie (GLI) om die ook aan te bieden. Er is vooral naar elkaar gekeken en te weinig met elkaar opgetrokken. Dat is jammer.
\end{abstract}

\section{Inleiding}

Uit een onderzoek van het NIVEL uit 2012 blijkt dat slechts $5 \%$ van de mensen met overgewicht via bijvoorbeeld de huisarts iets verandert aan zijn leefstijl [1]. Hiervan profiteert slechts $1,25 \%$ op de langere termijn. Die lage cijfers zijn onder andere te wijten aan het feit dat er geen aanbod was waar professionals naar kunnen verwijzen. Als er al een tijdelijk programma was, dan moest de patiënt daar vaak zelf voor betalen. Dat is een hoge drempel. Sinds 1 januari 2019 wordt de GLI vergoed uit het basispakket. Daarom is het nu tijd om de GLI met z'n allen op te pakken. Met gemeenten, met zorgprofessionals, zoals huisartsen, praktijkondersteuners, diëtisten en fysiotherapeuten, en met verzekeraars.

\section{Coaching op Leefstijl}

Zorgverzekeraar CZ heeft samen met de Universiteiten Maastricht en Tilburg, de beroepsvereniging leefstijlcoaches Nederland, de Academie voor Leefstijl en Gezondheid, en het Nederlands instituut voor Sport en Bewegen een programma opgesteld dat werkt. Het CooL-programma (Coaching op Leefstijl) is zo'n GLI

Dr. M. Johannesma · G. van Hoof $(\bowtie)$

Zorgverzekeraar CZ, Tilburg, Nederland

geert.van.hoof@cz.nl en het is bovendien een mooie samenwerking tussen de zorg en het gemeentelijke domein. Leefstijlcoaches werken samen met andere professionals, zoals buurtsportcoaches en fungeren als 'spin in het web'. Zo kan tegen acceptabele kosten blijvend resultaat worden geboekt. CZ heeft op die manier een structureel aanbod gecreëerd, dat voor iedereen toegankelijk en betaalbaar is.

Vaak zijn programma's vooral gefocust op gewichtsverlies. Dat is logisch, want gewichtsverlies is makkelijk te meten. Wij vinden echter dat je verder moet kijken, want bij een focus op alleen gewichtsverlies blijkt dat mensen vaak terugvallen in hun oude patroon - het bekende jojo-effect.

In het CooL-programma ligt het accent op duurzame gedragsverandering. De resultaten van een pilotonderzoek laten zien dat deelnemers op zowel de korte als de lange termijn gezonder eten en meer bewegen [2]. Het gaat om de kleine stapjes in de dagelijkse activiteiten en voeding. Eigenlijk bevordert de interventie vooral de intrinsieke motivatie.

Natuurlijk is CZ erg enthousiast over de resultaten van de pilot en trots dat het RIVM het programma als voorbeeld stelt om te laten zien hoe zorgverzekeraars en gemeenten kunnen samenwerken [3]. Maar het belangrijkste is dat de GLI in zijn algemeenheid echt geborgd wordt, dat deze gedekt wordt in de basisverzekering en dat we werken aan duurzame veranderingen. Met z'n allen. Leefstijlinterventies moeten dan ook voor iedereen toegankelijk en betaalbaar zijn. Je kunt ook zeggen dat je zelf verantwoordelijk bent voor een gezonde leefstijl. Sommige mensen hebben echter een steuntje in de rug nodig.

Naast het CooL-programma zijn er nog twee programma's die als GLI uit de basisverzekering vergoed kunnen worden: Slimmer en de Beweegkuur-GLI. Zorgverzekeraars zijn vrij om te bepalen welke programma's zij inkopen en bij wie ze dat doen. 
Vijf miljoen mensen komen voor de GLI in aanmerking, maar de ervaring leert dat $5 \%$ van de doelgroep echt zal deelnemen. Dat klinkt als een kleine groep. Maar het zijn toch al gauw 250.000 Nederlanders die daardoor steun krijgen om hun kwaliteit van leven en intrinsieke motivatie te verhogen en gezonder te leven, en uiteindelijk minder zorg nodig hebben.

\section{Brede samenwerking nodig voor de uitvoering van GLI's}

Veel beroepsgroepen, zoals leefstijlcoaches, diëtisten, fysiotherapeuten, huisartsen, buurtsportcoaches en zorgverzekeraars moeten nu de handen ineenslaan. De gecombineerde leefstijlinterventie, zoals het CooLprogramma, is nog lang niet overal geaccepteerd. Een aantal partijen twijfelt aan de competenties van leefstijlcoaches, omdat deze niet als zorgprofessional in het BIG-register zijn opgenomen. Leefstijl als medicijn vraagt echter om andere kennis en vaardigheden dan in de huidige opleidingen tot zorgprofessional worden aangeleerd. Mensen ondersteunen en stimuleren bij het aanleren van nieuw gedrag vraagt om een andere insteek dan een (para)medische behandeling. Dat is ook de reden waarom hiervoor in de kwaliteitsregisters van diëtisten, fysiotherapeuten en oefentherapeuten een aparte aantekening wordt gemaakt.

Ieder moet nu zijn rol oppakken. Nu de regels en voorwaarden duidelijk zijn heeft de minister van VWS op basis van een analyse van het RIVM extra geld aan het zorgbudget toegevoegd en hebben alle zorgverzekeraars de gecombineerde leefstijlinterventies in de polisvoorwaarden en inkoopdocumenten opgenomen. Om de kwaliteit en afstemming met de huisartsenzorg te borgen, is een verwijzing van de huisarts voorwaarde voor vergoeding. Daarnaast willen zorgverzekeraars om diezelfde reden de zorg bij voorkeur inkopen bij zorggroepen, vooral omdat een groot deel van de patiënten met diabetes mellitus type 2 en overgewicht voor de GLI in aanmerking komt.

Gemeenten moeten hun infrastructuur qua beweegaanbod ook voor deze doelgroepen (waaronder de inzet van de buurtsportcoach of gezondheidsmakelaar) op orde hebben en de aanbieders van de leefstijlinterventies moeten hun rol in het bestaande zorgnetwerk krijgen. Dat is heel veel keer 'moeten' achter elkaar. Maar de urgentie is dan ook groot. Veel verschillende beroepsgroepen krijgen de verantwoordelijkheid om het optimale uit de GLI te halen. Bij onzorgvuldig gebruik verliest deze immers snel zijn waarde. We moeten leren van best practices, voortdurend doorontwikkelen, adapteren en innoveren. De primair betrokkenen moeten zorgvuldig met de GLI omgaan, en dus niet gaan afkloven of 'cherry picken'. Goede monitoring door een betrouwbare registratie van de juiste uitkomstindicatoren, maar ook intervisie en supervisie zijn daarbij van essentieel belang.

\section{Kansen voor GLI's gaan benutten}

We zien helaas dat er veel zorggroepen hebben besloten om de GLI in 2019 niet aan te bieden. Deze zorggroepen geven aan behoefte te hebben aan duidelijke informatie en procesmatige ondersteuning. Zo is de wijze waarop de indicatoren voor de resultaatmeting worden verzameld nog niet bekend en is het ook nog niet duidelijk welke ICT nodig is. Daarnaast bestaan er ook op het financiële vlak nog onzekerheden - er is bijvoorbeeld verwarring over het feit dat er over deze nieuwe zorgprestatie btw wordt gerekend. ${ }^{1}$ Tot slot is het voor zorggroepen lastig dat zorgverzekeraars verschillen in hun inkoopbeleid. De genoemde zaken belemmeren het maken van contracteringsafspraken. Dat is erg jammer en een slechte start voor de implementatie van de GLI.

In het Nationaal Preventieakkoord, dat op 23 november jongsleden is vastgesteld, wordt onder andere ingegaan op het terugdringen van overgewicht en obesitas. In het kader van de samenwerking tussen zorg en preventie daarin is er in het bijzonder aandacht voor de belangrijke doorverwijzende rol van de huisarts met het oog op een goede, passende uitvoering van effectieve GLI's en de bredere obesitasproblematiek.

Het is mooi dat er binnen de zorgverzekering eindelijk serieuze aandacht voor preventie is en dat een pad wordt gebaand voor preventie van chronische ziekten. $\mathrm{Nu}$ zijn de zorgprofessionals, zorgverzekeraars en gemeenten aan zet om dit pad goed te bewandelen en eindelijk leefstijl structureel in te bedden in de curatieve én publieke sector!

Open Access This article is distributed under the terms of the Creative Commons Attribution 4.0 International License (http://creativecommons.org/licenses/by/4.0/), which permits unrestricted use, distribution, and reproduction in any medium, provided you give appropriate credit to the original author(s) and the source, provide a link to the Creative Commons license, and indicate if changes were made.

\section{Literatuur}

1. Koopmans B, Korevaar J, Nielen M, et al. NIVEL Overzichtsstudies: preventie kan effectiever! Deelnamebereidheid en deelnametrouw aan preventieprogramma's in de zorg. Utrecht: NIVEL; 2012.

2. Rinsum $C$ van. Prevention and treatment of obesity. The role of lifestyle coaches and health brokers. Proefschrift. Maastricht: Maastricht University; 2018.

3. Vooren NJE van, Dorst HDCA van, Buist Y, et al. Evaluatie Preventie in het Zorgstelsel. Samenwerking gemeenten en zorgverzekeraars ten aanzien van preventie in 2017 . Bilthoven: RIVM;2018.

${ }^{1}$ Er is inmiddels meer duidelijkheid over de btw-plicht: 1. GLI is btw-plichtig.

2. VWS verhoogt het budgettair kader voor de GLI.

3. NZA geeft zorgverzekeraars toestemming om het btw-bedrag bovenop het maxtarief te vergoeden. 